\title{
Is routine histopathological examination of FESS material useful?
}

\author{
Cindy van den Boer · Guy Brutel · Nico de Vries
}

Received: 24 June 2009 / Accepted: 3 September 2009 / Published online: 18 September 2009

(C) The Author(s) 2009. This article is published with open access at Springerlink.com

\begin{abstract}
Analysis of the clinical value of histopathological examination of material collected during functional endoscopic sinus surgery. Retrospective analysis of collected data of patients undergoing functional endoscopic sinus surgery over a 7-year period. Data were collected from a pathology database of the Sint Lucas Andreas Hospital, Amsterdam, The Netherlands. All material collected from 1,944 functional endoscopic sinus surgery cases in 1,695 patients (some patients underwent revision surgery) operated between 2000 and 2007 was examined histologically. Patients with a histological outcome different from chronic inflammation or polyposis nasi, were checked on indication of surgery, type of surgery and preoperative clinical suspicion for (pre)malignancy. The impact of the histological diagnosis on the clinical course was evaluated. Thirty-seven unusual diagnoses were reported: 18 cases of inverted papilloma, one squamous cell carcinoma, two malignant lymphomas, one leiomyosarcoma, eight squamous cell papillomas, one Churg Strauss syndrome, one Schneiderian papilloma, two cases of Wegener's granulomatosis and three cases of sarcoidosis. All other specimens were identified as chronic inflammation and/or nasal polyposis. Only two clinically significant, unexpected diagnoses, both inverted papilloma, have resulted from the histological investigation. We conclude that the close correlation
\end{abstract}

C. van den Boer $\cdot$ N. de Vries $(\square)$

Department of Otolaryngology/Head Neck Surgery,

Sint Lucas Andreas Hospital, P.O. Box 9243,

1006AE Amsterdam, The Netherlands

e-mail: n.vries@slaz.nl

G. Brutel

Department of Pathology, Sint Lucas Andreas Hospital,

P.O. Box 9243, 1006AE Amsterdam, The Netherlands between histopathology outcome and examination on clinical grounds or gross inspection indicates that routine histopathological examination of functional endoscopic sinus surgery material has little clinical value and it is questionable if this should be performed. In patients in whom there is a high degree of suspicion for (pre)malignancy, histopathological examination of functional endoscopic sinsus surgery material remains indicated.

Keywords Functional endoscopic sinus surgery · Histopathology outcome - Chronic rhinosinusitis .

Polyposis nasi

\section{Introduction}

Chronic rhinosinusitis (CRS) with/without nasal polyposis (NP) is a common disease, which affects annually approximately $16 \%$ of the population in the United States [1, 2]. Functional endoscopic sinus surgery (FESS) is indicated in patients with CRS when conservative treatment has (partially) failed or when massive polyposis is present. Other indications for FESS might be suspicion of (pre)malignancy and/or an increased risk of orbital, endocranial and/ or septic complications. [3-6]

In most of the institutes in the US and Europe, it is routine clinical practice to have FESS material investigated histologically to confirm the clinical diagnosis. The adagium is "if it is important enough to have it removed, it is important enough to have it investigated". However, it is a clinical reality that the clinical diagnosis of CRS with/without NP in patients undergoing FESS, is confirmed by histological investigation in almost all cases.

In only a very small number of patients other unexpected diagnoses such as premalignant (e.g., inverted papilloma), 
or malignant tumours are found. We were interested to examine how often histological examination identified pathology not expected preoperatively on clinical grounds and how far such a finding would alter the subsequent treatment and follow-up. Is routine histological investigation of all FESS material necessary or not?

\section{Materials and methods}

Between 2000 and 2007, 1,944 specimens collected from FESS from 1,695 patients (some patients underwent revision surgery) were histological examined in the Sint Lucas Andreas Hospital (SLAZ) in Amsterdam, The Netherlands. All collected FESS material was found by making use of a database (PALGA) with the search term "upper airways". Further selection was done by making use of information given about the surgeon, diagnosis, and origin of the material (nose or paranasal sinuses). Data collected about the patients included name, gender, patient registration number, date of birth, material, diagnosis with linked codes, surgeon and date of material collection. The average age of patient population was 48 years. $46 \%$ was female. As the site of removal and the procedure were coded from the clinical information, topography and procedure were not always certain.

All FESS material was investigated at the department of pathology at the SLAZ. The histological diagnosis was reported and filed in the database. Standard histological examination consisted of macroscopic investigation, fixation in formalin, often decalcification and microscopic examination of slides prepared with HE-staining on glass slide. No systematic slide review was done. Preparations were only reviewed if indicated.

Patient files were studied only in case of diagnosis other than chronic inflammation with/without NP. PALGA did not provide information about the indication for surgery. Therefore, we were not able to distinguish between routine and diagnostic indications of histopathological examination.

Significant nose bleeds, unilateral pathology, different aspect with nasendoscopy than normally seen with CRS with/without NP, palpable cervical lymph nodes, unexplained weight loss or unexplained constitutional symptoms (fever, fatigue) were regarded as warning signs for potential pathology other than CRS with/without NP, particularly (pre)malignant disease. In case of pathology other than CRS with/without NP, without preoperative clinical suspicion and with potential consequences for further treatment, the diagnosis was regarded as "clinical significant".

Costs of histological examination were calculated by making use of COTG (Central Organ of Rates in Health System). The costs were 47.10 euro per patient, independent of how many slides were prepared.

\section{Results}

Between 2000 and 2007, 1,944 different FESS specimens from 1,695 patients (some patients underwent revision surgery) were investigated microscopically. Most diagnoses were chronic inflammation and polyposis with/without eosinophilia. The histopathological diagnosis was NP with/ without inflammation in 1,101 patients $(65 \%)$ and chronic inflammation in 557 patients $(33 \%)$. In $37(2.1 \%)$ of the 1,695 patients, the histopathological diagnosis was different (Table 1). There were 18 inverted papillomas, 7 squamous cell papillomas, 2 malignant lymphomas, 1 Churg Strauss syndrome, 1 leiomyosarcoma, 1 Schneiderian papilloma, 2 cases of Wegener's granulomatosis, 3 cases of sarcoidosis, 1 papilloma with metaplastic changes and 1 squamous cell carcinoma (Table 2).

The clinical files of these 37 patients were analysed, and the indication for surgery and risk factors were noted (Table 3). 27 patients were seen with unilateral pathology and were therefore suspicious for pathology other than CRS with/without NP, e.g., premalignancy, malignancy or other divergent diagnoses. In these cases FESS was both a diagnostic procedure and treatment. Only four patients were diagnosed with a malignancy. In all four this was suspected preoperatively and a FESS was performed to obtain material for histology. All four patients complained of pain, nose bleeds and reduced nasal passage. Furthermore, during physical examination an unilateral atypical mass with (sub)total nasal obstruction was seen. None of these four

Table 1 Histological confirmed diagnoses of 1,695 patients

\begin{tabular}{lcc}
\hline Diagnostic terms & $\%$ & $N=1,695$ \\
\hline Polyposis (with/without inflammation) & 65 & 1,101 \\
Chronic inflammation & 32.9 & 557 \\
Other diagnoses & 2.1 & 37 \\
\hline
\end{tabular}

Table 2 Histological confirmed 'other diagnoses'

\begin{tabular}{lc}
\hline Other diagnoses & $N=37$ \\
\hline Squamous cell papilloma & 7 \\
Inverted papilloma & 18 \\
Squamous cell carcinoma & 1 \\
Leiomyosarcoma & 1 \\
Malignant lymphoma & \\
CLL/SLL & 1 \\
Extra nodal NK/T-cell & 1 \\
Sarcoidosis & 3 \\
Wegener's disease & 2 \\
Churg Strauss syndrome & 1 \\
Papilloma + metaplastic changes & 1 \\
Schneiderian papilloma & 1 \\
\hline
\end{tabular}


Table 337 diagnoses with indication for functional endoscopic sinus surgery and side of pathology location

\begin{tabular}{|c|c|c|c|c|}
\hline \multirow[t]{2}{*}{ Character diagnosis } & \multirow[t]{2}{*}{ Diagnosis } & \multirow[t]{2}{*}{ Indication } & \multicolumn{2}{|c|}{ Pathology located } \\
\hline & & & Unilateral & Bilateral \\
\hline \multirow[t]{3}{*}{ Malignant } & 2 malignant lymphomas & Clinical suspicious & 1 & \\
\hline & 1 carcinoma & ddx: recurrent IP & 1 & \\
\hline & 1 leiomyosarcoma & Clinical suspicious & 1 & \\
\hline \multirow[t]{6}{*}{ Pre-malignant } & 18 inverted papilloma & 1 unknown primary & 1 & \\
\hline & & 5 polyposis nasal & 3 & 2 \\
\hline & & 11 atypical polyposis/IP & 10 & 1 \\
\hline & & 1 malignancy/fibroma & 1 & \\
\hline & 1 papilloma + metaplastic changes & $\begin{array}{l}\text { Polyposis/IP } 1 \text { side } \\
\text { suspicious }\end{array}$ & & 1 \\
\hline & 1 schneiderian papilloma & Papilloma & 1 & \\
\hline \multirow[t]{4}{*}{ Benign } & $\begin{array}{l}7 \text { squamous cell papilloma } \\
\text { ( } 1 \text { follow up-verrucous carcinoma) }\end{array}$ & $\begin{array}{l}4 \text { atypical papilloma } \\
3 \text { sinusitis }\end{array}$ & 7 & \\
\hline & 3 sarcoidosis & $\begin{array}{l}1 \times \text { granulation } \\
1 \times \mathrm{ddx} \text { : sarcoidosis, } \mathrm{TB} \\
1 \times \text { sinusitis }\end{array}$ & & 3 \\
\hline & 2 Wegener's disease & $2 \times$ clinical suspicious & & 2 \\
\hline & 1 Churg Strauss & Clinical suspicious & 1 & \\
\hline
\end{tabular}

$d d x$ Differential diagnosis, $I P$ inverted papilloma, $T B$ tuberculosis

patients had enlarged lymph nodes in the neck. Four patients have passed away. There were three patients with bilateral pathology visible at physical examination, with unilateral inverted papilloma, and on the other side NP. Of the patients with inverted papillomas, one had a positive family history of NP, and one patient had a suspicious unilateral atypical polyposis.

In two cases, clinically appearing as bilateral NP, a clinical significant diagnosis was found. Both had indeed bilateral NP, but with an unexpected unilateral inverted papilloma as well.

The costs of histological research of the FESS material per case were $€ 47.10$. Total costs of all the FESS material were $47.10 \times 1,695=€ 79,834.50$ (annually $€ 11,404.90$ ). The costs to find the 2 clinical significant diagnoses (inverted papilloma) were $47.10 \times(1,695-35)=€ 78,186$.

\section{Discussion}

In $100 \%$ of patients with CRS without polyps (32.9\%, Table 1), the clinical diagnosis was confirmed by histological examination. In the patients with CRS with polyps (65\%, Table 1), the clinical diagnosis was confirmed with the exception of only two patients who had an unexpected inverted papilloma in bilateral polyposis nasi. In only $2.1 \%$, histology other than CRS with/without NP was found. In these cases, with the exception of the above two patients, it was preoperatively expected to find histology other than CRS with/without NP.
No unexpected malignancies were found. In one case of a malignancy, an unilateral tumour was initially diagnosed as granulation and squamous cell proliferation without signs of malignancy. A relapse occurred next to initial reduction after treatment with corticosteroids. Clinical suspicion resulted in a second biopsy showing a verrucous carcinoma. In six patients ( 3 cases of sarcoidosis, 2 cases of Wegener's disease and 1 Churg Strauss syndrome), a clinical diagnosis was already established preoperatively and subsequently confirmed by histological examination [7].

In this study, first, it was not possible in all cases to assess the exact site of the collected material (for example in which sinus, or nasal compartment). Second, the exact procedure of surgery was not always filled on the pathology form. It is however unlikely that this has led to a bias in the results.

In two patients with bilateral polyposis and unexpected unilateral papilloma inversum, the treatment and follow-up has remained unaltered so far. It is our standard policy to keep both massive NP and inverted papilloma under long term follow-up. Till date, no revision surgery was needed. In the available retrospective data we were unable to find how many times a suspicion of inverted papilloma was not confirmed.

The other divergent diagnoses were all clinically suspicious and contained a specific request to the pathologist. This is not only quality control, but pure confirmation or exclusion of suspected other pathology. The strong correlation between clinical inspection and pathologic diagnosis of FESS material raises the question of need of histological confirmation $[8,9]$. If the surgeon is left with the choice of requesting pathology investigation or discarding specimens 
there is a risk of missing relevant diagnoses. Even when the choice has been made to dispose the tissue specimens without pathology testing, a less experienced clinician might make a wrong choice [10]. If histological examination has a little clinical value, it is interesting to discuss why and when pathology of FESS material is needed [11, 12].

One reason to continue routine examination of FESS material could be to look at eosinophils versus neutrophils [13-15]. Although there is some believe that this has implications for aftercare, such as maintenance corticosteroid therapy, present guidelines give little support for different postoperative policies in neutrophilic and eosinophylic polyps [16].

The financial aspect warrants attention in present health care with cost labels on every diagnostic test and treatment. The present Dutch Health care system has an all-inclusive price for the whole diagnostic work up and treatment of a certain diagnosis. In nasal polyps, this includes laboratory, radiology and pathology investigations and this might stimulate clinicians not to check their diagnoses histologically, because it lowers the price of diagnosis and treatment. The cost of finding the two unsuspected clinical significant diagnoses was $€ 78.186$. On an annual basis and if the costs are calculated per patient, however, it is relatively inexpensive compared to other clinical tests and imaging. Costs of clinical procedure of FESS in Sint Lucas Andreas hospital are $€ 4,227.95$ per patient, in daycare these costs amount $€ 2,790.35$ per patient. Only a small percentage of these costs, namely $1.1 \%$ of clinical FESS treatment and $1.7 \%$ of daycare treatment, are due to (routine) histopathologic examination.

On contrary, this cost saving argumentation is the appeasement given to patients undergoing FESS when histological investigation excludes (unsuspected) potentially adverse lesions and confirms the (suspected) diagnosis CRS with/without polyps.

The Sint Lucas Andreas hospital is not a referral centre for extremely complicated FESS cases or skull base surgery. Patients are mainly referred in case of suspicion of CRS with/without NP, but not specifically for rare FESS indications such as (pre)malignancy or congenital lesions. Conclusions and patient population might be different in referral centres. Finally, we are very much aware that the retrospective nature might be an important shortcoming of the study and the best way to really assess the value of routine histopathological examination of FESS material would be to perform a large scale prospective study.

\section{Conclusion}

It is rare to find clinical significant diagnoses in histopathology outcome of functional endoscopic sinus surgery. The close correlation between clinical or gross inspection and histopathology outcome indicates that in patients with suspected CRS with/without NP histopathology has little to no clinical value. It might be considered to set up a prospective study to further elucidate this question.

Open Access This article is distributed under the terms of the Creative Commons Attribution Noncommercial License which permits any noncommercial use, distribution, and reproduction in any medium, provided the original author(s) and source are credited.

\section{References}

1. Anand VK (2004) Epidemiology and economic impact of rhinosinusitis. Ann Otol Rhinol Laryngol Suppl 193:3-5

2. Benninger MS, Sedory Holzer SE, Lau J (2000) Diagnosis and treatment of uncomplicated acute bacterial rhinosinusitis: summary of the Agency for Health Care Policy and Research evidence-based report. Otolaryngol Head Neck Surg 122(1):1-7

3. Behnecke A, Mayr S, Schick B, Iro H, Raithel M (2008) Evaluation of ECP release from intact tissue biopsies from patients with nasal polyps. Inflamm Res 57(Suppl 1):S65-S66

4. Bhattacharyya N (2007) Influence of polyps on outcomes after endoscopic sinus surgery. Laryngoscope 117(10):1834-1838

5. Watelet JBH, Eloy PH, van Cauwenberge PB (2007) Drug management in chronic rhinosinusitis: identification of the needs. Ther Clin Risk Manag 3(1):47-57

6. Ragab SM, Lund VJ, Scadding G (2004) Evaluation of the medical and surgical treatment of chronic rhinosinusitis: a prospective, randomised, controlled trial. Laryngoscope 114(5):923-930

7. Tritt S, McMains KC, Kountakis SE (2008) Unilateral nasal polyposis: clinical presentation and pathology. Am J Otolaryngol 29(4):230-232

8. Kale SU, Mohite U, Rowlands D, Drake-Lee AB (2001) Clinical and histopathological correlation of nasal polyps: are there any surprises? Clin Otolaryngol Allied Sci 26(4):321-323

9. Romashko AA, Stankiewicz JA (2005) Routine histopathology in uncomplicated sinus surgery: is it necessary? Otolaryngol Head Neck Surg 132(3):407-412

10. Nakhleh RE (2006) What is quality in surgical pathology? J Clin Pathol 59(7):669-672

11. Diamantopoulos II, Jones NS, Lowe J (2000) All nasal polyps need histological examination: an audit-based appraisal of clinical practice. J Laryngol Otol 114(10):755-759

12. The Royal College of Pathologists (2005) Histopathology of limited or no clinical value, 2nd edn. RCPath, London, UK. Available at http://www.rcpath.org/publications

13. Kountakis SE, Arango P, Bradley D, Wade ZK, Borish L (2004) Molecular and cellular staging for the severity of chronic rhinosinusitis. Laryngoscope 114(11):1895-1905

14. Lee JT, Kennedy DW, Palmer JN, Feldman M, Chiu AG (2006) The incidence of concurrent osteitis in patients with chronic rhinosinusitis: a clinicopathological study. Am J Rhinol 20(3):278-282

15. Rudack C, Sachse F, Alberty J (2004) Chronic rhinosinusitisneed for further classification? Inflamm Res 53(3):111-117

16. Thomas M, Yawn BP, Price D, Lund V, Mullol J, Fokkens W (2008) EPOS primary care guidelines: European position paper on the primary care diagnosis and management of rhinosinusitis and nasal polyps 2. Prim Care Respir J 17(2):79-89 